\title{
Implementation of MOOC platforms into teaching English to IT specialists
}

\author{
Svitlana Symonenko ${ }^{1, *}$, Nataliia Zaitseva ${ }^{1, * *}$, and Viacheslav Osadchyi ${ }^{2, * * *}$ \\ ${ }^{1}$ Dmytro Motornyi Tavria State Agrotechnological University, 18 Bohdana Khmelnytskoho Ave., Melitopol, 72312, Ukraine \\ ${ }^{2}$ Bogdan Khmelnitsky Melitopol State Pedagogical University, 20 Hetmanska Str., Melitopol, 72300, Ukraine
}

\begin{abstract}
The paper deals with the issue of application possibilities of MOOC platforms in IT specialist training. It is emphasized that this problem is urgent due to the coronavirus pandemic which caused reconsideration of educational approaches, means and tools. In the study the analysis of the most demanded massive open online course platforms in terms of IT specialist training is presented. Challenges of MOOCs for teaching and learning foreign languages are highlighted. Profession-related, soft skill mastering and English learning courses have been scrutinized in terms of their content and user-friendliness by teachers and students of two universities. Design, layout, topics, communities, documentation, and application availability have been evaluated and ranked. Three online English courses of similar purpose on Coursera, FutureLearn and Prometheus have been compared and ranked with the aim to advise the most efficient one to senior undergraduates striving to be employed in Ukraine and abroad in the multicultural IT environment.
\end{abstract}

\section{Introduction}

The coronavirus pandemic has drastically changed the way of living, education and entertainment all over the world [1-8]. Due to national lockdowns and imposition of quarantine educational establishments of different levels had to be closed at the beginning of 2020 , so governments, local administrations, educators and students had to find appropriate ways and tools to continue and even to complete education. Numerous attempts to continue learning and teaching have been made: new educational online courses have been developed, existing online courses have been rearranged and updated, new practices of teaching and learning have been introduced, TV-programs on different subjects have been created and broadcast on national TV channels, various websites, pages in social networks for teacher and student support have been initiated.

Simultaneously, enrollments at massive open online courses boosted. The statistics [9] shows that registrations at Coursera and Udemy in March-April 2020 were correspondingly $640 \%$ and $400 \%$ higher than during the same period in 2019. These figures can be explained by presentation of free courses to university partners and consequent possible participation in courses by university students.

\section{Analysis of MOOC implementation in higher education}

Massive open online courses (MOOCs) [10-12] have had their history since the beginning of the 21 st century which comprises quite opposite periods in their existence: from

\footnotetext{
*e-mail: svitlana.symonenko@tsatu.edu.ua

**e-mail: nataliia.zaitseva@tsatu.edu.ua

***e-mail: poliform55@gmail.com
}

the explosive early growth and declaration of 2012 as the "Year of the MOOC" [9] to almost passing into oblivion and even the "death" [13].

The term MOOC was coined by Dave Cormier in 2008. George Siemens who was an inspirer of MOOC introduction into education defined it as "an online course with the option of free and open registration, a publicly shared curriculum, and open-ended outcomes" [14]. According to Wikipedia [15] (last accessed 10 November 2020, the definition is regularly updated) "a massive open online course is an online course aimed at unlimited participation and open access via the web. In addition to traditional course materials, such as filmed lectures, readings, and problem sets, many MOOCs provide interactive courses with user forums or social media discussions to support community interactions among students, professors, and teaching assistants, as well as immediate feedback to quick quizzes and assignments".

M. Perifanou [16] gives the following explanation of the acronym MOOC, stating that MOOC stands for Massive Open Online Courses, where the term "massive" refers to the large number of participants taking part in the course; the term "open" means a course without any charges or any definite conditions to join the course; the term "online" indicates that courses are available on the web with the free content.

According to the MOOC-BOOK, an open resource for business, higher education institutions and learners, in order to make use of MOOCs [17] these courses have made it possible to study at any suitable time, in any place, with lower costs or free, in a flexible mode. In addition, participants can interact with different people, join new groups of people with joint interests, generate new ideas, and originate innovative projects in different fields. 
N. Alhazzani [18] emphasizes that MOOCs are based on the four major principles of Siemens connectivism:

- compilation (resources are added to the webpage during the course in contrast to traditional courses where resources are arranged at the beginning),

- modification (users collect, sort and manipulate materials in their own manner),

- re-employment (users study materials and express their opinions on the web in different ways),

- dissemination of distinctive ideas (users exchange their views with other users).

$\mathrm{N}$. Alhazzani insists that according to his research MOOCs have direct impact on higher education in terms of improving learning outcomes, developing student skills, and fostering effective communication with values.

S. Gallagher and J. Palmer in their article [19] state that the last decade has been a time of education "alternatives, including massively open online courses, industry-driven certification programs, and coding bootcamps", emphasizing that higher education has moved much slower "to a more digitally-driven, outcomes-focused business model".

Having studied participation in MOOCs J. Reich and J. Ruipérez-Valiente [20] state that the majority of participants do not return after the first year of their study, MOOC participants come from the most prosperous countries, and the course completion rate has been low. Diane Peters having reviewed information on MOOCs for ten years of their existence gives more exact figures of MOOC completion rates asserting that they are equal to 5\% [21].

S. Lohr in review [22] brings to mind the fact that at the time of their introduction MOOCs were "tech-fueled insurgents destined to disrupt the antiquated ways of traditional higher education". He presents some MOOC statistics on completion of the courses and stresses that $10 \%$ of students completed free courses, $40-90 \%$ of participants completed paid courses. The completion rates, certain drawbacks of MOOCs, as the author notes, caused a punch line "Remember the MOOCs?" among academics.

The situation with MOOCs dramatically changed in spring 2020 when these courses regained their popularity. Statistical reports confirm that the number of new users in the most popular MOOCs increased by hundreds percent. In April 2020 Coursera, edX, and FutureLearn enrolled as many new students as in the whole of 2019. About 25$30 \%$ of total registered users on MOOCs came after the pandemic [23]. The analysis of five most widely used platforms is presented in table 1 .

Much research has been done on the use of MOOCs before and after declaration of COVID-19 a worldwide pandemic. T. Chen et al. [24] have made an attempt to study the online education platforms before and after the outbreak of COVID-19 in terms of online user experience. The research found that before the outbreak of the pandemic the main concerns were "the access speed, reliability, and timeliness of video information transmission of the platform". The outbreak of the pandemic changed these concerns shifting to "course management, communication and interaction, learning and technical support services of the platform" with the user experience as the most significant one. Researchers have proposed to refine four main aspects of online education platforms: improving support service, improving the convenience of interactive communication, optimizing the ease of use, and enriching platform resources.

L. Ma et al. [25] studying the mixed teaching mode in the pandemic situation reveal the following drawbacks of MOOCs:

1) lack of direct communication between teachers and students;

2) low learning efficiency due to visual fatigue because of constant work with electronic devices and insufficient teacher supervision;

3) limitations of the learning environment.

\section{Challenges of MOOCs for teaching and learning foreign languages}

Facing challenges of 2020 prominent educational establishments have made significant efforts to ensure equal educational opportunities for all the learners worldwide. MOOCs which earlier were considered to be longlife learning instruments for filling gaps in knowledge upgrading and reskilling, became paramount studying venues for learning various disciplines, including foreign languages [26]. Moreover, MOOCs allow to follow the basic principles of foreign language teaching: deduction, student orientation, purposefulness and the communicative content of lessons [27].

I. Duru et al. [28] classify studies on investigating behaviours of second language learners within MOOCs as:

1. Participant engagement in a MOOC which is delivered in a language other than English.

2. English language learners engagement in a MOOC which is delivered in English.

3. English as a second language learners engagement in a language $\mathrm{MOOC}$ which is authored for learning the English language.

4. English as a second language learners engagement in a MOOC which is delivered in English.

Studying the issue of workplace training, particularly learning English for Occupational Purposes in MOOCs, $\mathrm{K}$. Rafiq et al. [29] give the following benefits of MOOCs both for employers and employees:

- self-paced learning environment which is crucially important for working people,

- lifelong learning opportunities, which foster acquisition of new knowledge and skills necessary for the workplace and encourage gaining online-based learning experience,

- professional development by ensuring active participation of learners in the course acquiring skills vital for organisations, 
Table 1. Factfile of MOOC platforms (retrieved from open sources)

\begin{tabular}{lllllll}
\hline MOOC & Number of students & Number of courses & Application & Registration & Certificate & Languages \\
\hline EdX & $33 \mathrm{mln}$ & 3,000 & Android, iOS & Obligatory & + Free/paid & English \\
Coursera & $60 \mathrm{mln}$ & 3,900 & Android, iOS & Obligatory & + paid & Multilanguage \\
FutureLearn & $10 \mathrm{mln}$ & 1,600 & - & Obligatory & + Free/paid & English \\
Udemy & $35 \mathrm{mln}$ & 130,000 & Android, iOS & Obligatory & + Free/paid & Multilanguage \\
Openlearning & $2.5 \mathrm{mln}$ & 3,600 & Android, iOS & Obligatory & + Free/paid & English \\
\hline
\end{tabular}

- free training which gives the chance to study without any payments making the education cost-effective and time-wise.

Definitely, MOOCs have certain drawbacks for students and teachers. One of the most significant disadvantages is the lack of personalization. A. A. Qaffas et al. [30] studying optimal personalization strategy in MOOCs state that learners are unique, have their own potential and study in their own manner which can be different from other students. Therefore, personalization of MOOCs is the strategic task of course developers.

One of the most challenging drawbacks is the absence of real-time connection of teachers and students. R. Furtado [31] insists that "MOOCs are an example of asynchronous learning", therefore there is no simultaneous interaction between students and teachers.

P. Raine states that not every participant need is satisfied by the MOOCs as DuoLingo and Busuu aimed at studying foreign languages, since students may need to practice particular aspects of foreign languages, they also may require the language content specially made for a particular student. The researcher also considers a MOOC not only as a learning tool and resource, but also as a promising "avenue for experimentation and research" [32].

M. Israel [33] reveals that integrating MOOCs into traditional classroom settings requires high motivation and additional time for instructors to use MOOCs in the educational process which increases the workload. D. Bruff et al. insist that this challenge is caused by the necessity of complying with coupling and cohesion where coupling means the "extent of dependency between online and inclass components" and "cohesion refers to the relatedness of the course content overall" [34].

According to the research of polytechnic lecturer acceptance of using massive open online courses for teaching English as a second language by N. Rubaai and H. HashimInter [35] there are five challenges faced by course participants:

1) absence of Internet connection or poor Internet connection which can cause demotivation of students to participate in the course;

2) the necessity to spend additional time while learning in MOOCs;

3) changes in student attitudes;

4) the lack of application knowledge resulting in difficulties in dealing with technologies;
5) instability of MOOCs in terms of student progress monitoring.

M. A. Perifanou, A. A. Economides [36] propose a list/framework of the core course elements that a MOOC for language learning should have. These core elements are:

a) content (authentic educational resources; use of multimedia/technology; variety of activities that promote all basic language skills and support cultural awareness);

b) pedagogy (communication, collaboration, collective intelligence; autonomy, engagement-motivation; playful/game based learning, number of instructors);

c) assessment (ongoing assessment/ scaffolding, final assessment; evidence-based improvement, feedback);

d) community (social community building);

e) technical infrastructure (maximum number of participants, platform performance, security, usability);

f) financial issues (profit, charges for course or certification/ accreditation).

The list can be used for designing and evaluating the MOOC environment.

\section{Practical aspects of implementation of MOOC platforms into IT specialist training}

The Covid-19 pandemic has changed the attitude of all educational process agents towards distance learning: the students turned to it in order to become certified specialists in their professional and related spheres and the instructors implemented online learning resources into teaching their subjects in order to diversify instructional materials through involving students into online activities, to add culturological and linguistic aspects into undergraduate education, to enhance student motivation to learn. One of the most beneficial features of online courses (alongside with their completion and being awarded a certificate) is the possibility to select the themes and to realize one's own need in improving the specific skill or in filling a gap in one's knowledge through partial studying the course. Furthermore, since the most advanced online platforms worldwide are Coursera, FutureLearn and Udemy, most courses displayed on them are in English, which is a powerful incentive and concurrently means for improving one's English language skills. In addition, personal 
MOOC verified certificates of achievement issued by the educational establishment that provided the online course give students the opportunity to receive university transfer credit at Ukrainian universities. The grounds for the transfer are corresponding university regulations and procedures.

The authors of this study have chosen namely the students majoring in IT as MOOC explorers during the Covid pandemic due to their strong motivation for learning and awareness of three aspects reflecting the successful employment terms:

1) a globalization trend within the labour markets of the countries with the most progressively functioning ICT companies;

2) inevitable superiority of confirmed various skills and experience over university certificates of degree in the view of HR managers;

3) necessity of demonstrating their English proficiency and strong motivation for developing their own preliminary level of foreign language command.

MOOC platforms are simultaneously means of improving English and a tool for acquiring new and upgrading nascent knowledge (e.g. profession-related) and skills (like soft skills) through English. The variety of spheres, specifications, themes and educational means within courses as well as diversity of certificate eligibility criteria ensure that both user categories are satisfied those who need learning beyond schooling, and those who need a certificate of achievement for their prospective employment.

The teachers of Dmytro Motornyi Tavria State Agrotechnological University and Bogdan Khmelnitsky Melitopol State Pedagogical University who lead the study groups for students with advanced command of English, well-developed communicative skills and driving ambition of becoming a highly demanded IT professional, have developed a strategy to keep the participants of their groups motivated to maintain intense learning in the prolonged and undefined quarantine period. In spring 2020, most MOOC platforms decided to support potential users in the difficult times of the epidemic and succeeding financial crises. For instance, the most prominent MOOC Coursera platform has changed payment and certificate eligibility terms in order to allow access for more learners. Therefore, nine online courses have been selected and introduced to the IT specialists-to-be - they cover three educational aspects on three educational platforms - Coursera, FutureLearn and Prometheus.

The first aspect is a profession-related course on $\mathrm{Cy}$ ber Security compiled by educators of universities in the USA and the UK (in English) and from a Ukrainian university (in Ukrainian). The second aspect has been aimed at various thinking skills development - creative, critical, logical and design thinking. The Coursera and FutureLearn courses are introduced by educational establishments, whereas the course on the Ukrainian language on the Prometheus platform has been adapted and translated from a business school course. The remaining three online courses are the courses to which the group participants have been emphatically pointed by their English teachers. They are English for specific purposes courses specifically selected to meet the undergraduates' need to search for and to get a job and to be afterwards an effective employee in the English speaking professional environment.

The detailed information on the mentioned above nine courses and on their compilers as well as the grading according to the 5 point grading scale by the study group participants is displayed in table 2 .

At the end of the spring term the study group participants were offered to enroll in the represented courses and to share their progress reports within the courses as participants and users of both desktop and mobile versions at the beginning of the autumn term. The students were also asked to analyse the website design, the site map and the layout, and what is more significant, the site userfriendliness. The study group participants have stressed the following positive aspects of learning beyond classroom: constant availability of entire course learning material, possibility of several topic repetitions and sufficient revision of puzzling themes, choosing their own learning time and pace, absence of annoying classroom competition, prior evaluation objectiveness, and various multinational community, equally motivated to succeed. The overall results have shown the course participants' strong preference for the Coursera platform, succeeding platforms are FutureLearn and Prometheus.

The Coursera platform has the first position in ranking by study group participants. The adaptive web design, and therefore fully functional mobile Android and iOS versions make it possible to use the platform on portable devices. The page design resembles an ordinary document, which is not overloaded visually, the colour palette is comfortable for users. The menu on the platform is easy to understand, it is quite logical and simple. All space on the page is used, and there is no overload in information blocks. Navigation is comfortable, visual ergonomics harmonizes well with the content of the pages. The beneficial feature of the Coursera platform is the availability of applications for Android and iOS.

The first aspect noted by the group teachers was foreign language learning. Good command of English is not only the precondition for prospective employment in Ukraine and abroad, but also a major prerequisite for application for a master course at all Ukrainian universities. Strong competition for state-funded postgraduate education among the applicants is the less powerful incentive than the chance not to be enrolled in the study at all if the demonstrated English level is insufficient. As the group participants are mostly senior students, who are aware of the forthcoming National entrance exam, they willingly signed up for the offered English courses.

The English for Career Development by Coursera, created by the University of Pennsylvania, is intended for learners who want to improve their English language skills and plan to be acquainted to the job search process in the USA. The course comprises five units covering the U.S. job application process, resume writing, cover let- 
Table 2. Students' grading of courses on MOOC platforms

\begin{tabular}{|c|c|c|c|}
\hline Courses & Coursera & FutureLearn & \\
\hline $\begin{array}{l}\text { Profession- } \\
\text { related } \\
\text { course }\end{array}$ & 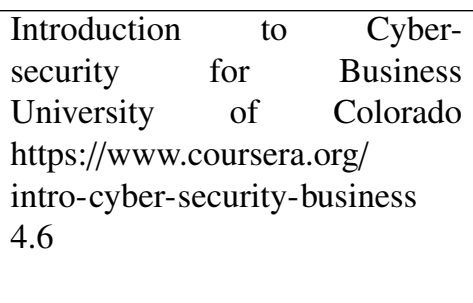 & $\begin{array}{l}\text { Become } \\
\text { Security }\end{array}$ & $\begin{array}{lr}\text { Information } & \text { Security } \\
\text { Basics (in } & \text { Ukrainian) } \\
\text { Igor Sikorsky } & \text { Kyiv } \\
\text { Polytechnic } & \text { Institute } \\
\text { https://courses.prometheus. } \\
\text { org.ua/courses/KPI/IS101/ } \\
\text { 3.8 }\end{array}$ \\
\hline $\begin{array}{l}\text { Soft skill } \\
\text { course }\end{array}$ & $\begin{array}{l}\text { Creative Thinking Tech- } \\
\text { niques and Tools for Success } \\
\text { Imperial College London } \\
\text { https://www.coursera.org/ } \\
\text { creative-thinking-techniques- } \\
4.4\end{array}$ & $\begin{array}{l}\text { Logical and Critical Thinking } \\
\text { The University of Auckland } \\
\text { https://www.futurelearn.com/ } \\
\text { logical-and-critical-thinking } \\
4.0\end{array}$ & $\begin{array}{l}\text { Design Thinking for In- } \\
\text { novation (in Ukrainian) } \\
\text { University of Virginia, Dar- } \\
\text { den School of Business } \\
\text { https://courses.prometheus. } \\
\text { courses/course-v1: } \\
\text { Prometheus+DTI101+2017_T3 } \\
4.0\end{array}$ \\
\hline $\begin{array}{l}\text { English } \\
\text { for specific } \\
\text { purposes }\end{array}$ & $\begin{array}{l}\text { English for Career Development } \\
\text { University of Pennsylvania } \\
\text { https://www.coursera.org/learn/ } \\
\text { careerdevelopment }\end{array}$ & $\begin{array}{l}\begin{array}{l}\text { English for the Workplace } \\
\text { British } \\
\text { https://www.futurelearn.com/ } \\
\text { workplace-english }\end{array}\end{array}$ & $\begin{array}{l}\text { English for Career Ad- } \\
\text { vancement (in Ukrainian) } \\
\text { University of Pennsylvania } \\
\text { https://prometheus.org.ua/ } \\
\text { english }\end{array}$ \\
\hline
\end{tabular}

ter writing, networking and interview skills. Each unit includes educational videos on vocabulary and grammar explanation with following comprehension tasks, reading tasks and activities, writing tasks for peer-graded assignments. Each unit also has additional resources and exercises (reading tasks and practice quizzes) which are not obligatory for getting the course certificate.

Videos in the course are presented by the course authors, who are English specialists of the leading US universities. The contents of the videos explain the peculiarities of vocabulary and grammar usage, comprehension is checked while watching, but it is not graded. The playback rate of videos can be regulated in accordance with the student level of knowledge. English transcripts and subtitles, French, Russian, Thai, and Spanish subtitles for videos are available and can be downloaded on students' computers. Students can also make their notes by capturing a screen, pressing the "Save Note" button while watching videos.

Reading tasks comprise authentic texts from journals, magazines, newspapers or other current resources, some reading content has audio files for practicing correct pronunciation. Texts for reading have two versions according to their level of difficulty: basic or advanced, the latter can be a challenge for students as authors of the course state. Comprehension activities include question quizzes (multiple-choice questions, true/false statements, flash card activities, writing tasks). $70 \%$ or more correct answers guarantee the successful course passing. In case of low grades participants can reattempt to improve their grades.

Writing assignments, for the most part, are aimed at formulating student opinions, using comparisons and contrasting the job search stages in the USA and students' native countries. All the answers are to be original, not borrowed, and as it is stated on the page if they are, this "may result in permanent failure of this course or deactivation of the Coursera account".

Certain periods of learning are scored by unlockable achievements in the form of the game success (getting a business attire, finding a job advertisement, etc). The Coursera Verified Certificate is awarded at the end of the course in case of successful learning. The certificate is not free, but participants can apply for financial aid on the course to get it.

The additional benefit of the course is the discussion forum where all the participants may consider different questions which can arise in separate week forums.

The FutureLearn platform has been ranked second by the study group participants. Its main page has the adaptive web-design, the visual content with tablet aspect ratio and visually simplified material presentation. All of the mentioned above is beneficial for distance learning on portable devices and smartphones. The colour match is bright and the main page looks informal and not informative due to the negative space layout. Nevertheless, the overwhelming white background drives users' attention towards the content elements through visual force concentrated on them and their bright colours. The drop down navigation reveals the intuitive user interface of the menu - numerous links with appropriate minimalist icons. In the rest of the page blocks, text descriptions are short, but all the necessary information is represented in linked images (pictures and partner logos), which direct users to corresponding URLs. The benefit of the mentioned simplified design is the possibility of making a choice: three top subjects are highlighted, succeeded by the View-all-subjects linked button. Four more featured courses are displayed below and complemented by the View-all-courses button, too. 
In the mobile version, the colour tension strains users' attention by focusing it on key points of the website, which are few in number but instructive and explicative due to linked visuals. The main page scrolling is resulting and fast because adaptive design selects the best layout for the current screen size and in so doing the block number is moderate.

Being a participant of the English for the Workplace course on the FutureLearn platform, learners cover four following topics: finding a job, interviews, starting a job, working together.

Doing the course, participants work over audio and video instructional material and explanatory articles not exceeding 600 characters. The advantage and interactive feature of the course is Facebook live. This live broadcast is an educational session with the course lead educators, who answer the learners' questions posted in comments. The quizzes covered in each section of every week test both content comprehension and the grammar mastering level. The linear course structure is optional, users are not directed to proceed in strict succession and may skip activities and even quizzes, which is beneficial for avoiding losing interest and demotivation due to lack of time or grammar task complexity. Nevertheless, learners are notified via email about the next week's start and presented its content, which stimulates the participants to return to the course. Moreover, the free course access expires in 14 days after the last week ends, which is the best incentive to complete the course in time. To obtain the FutureLearn certificate a course participant must buy unlimited access to hundreds of FutureLearn short courses or upgrade on the specific course for a fee, complete $90 \%$ of the course steps and score over $70 \%$ on average across all course tests. No verified certificate is issued.

The FutureLearn platform demonstrates the comprehensive content approach and advanced user-friendliness. Its web design is uncommon but resultative, its call to action buttons are unobtrusive and at the same time effective. The ground concept of the platform is that course selection and progressing within courses is a combination of free choice of activities succession and a learner's selfdiscipline. The most beneficial feature is the FutureLearn community, willing to share, to peer-review and to assist other participants in mastering a course material.

The Ukrainian Prometheus MOOC platform has been ranked number three by the IT experts-to-be. The course attendants unanimously noted the obsoleteness of the visuals of the Prometheus platform main page and the inconsistency of the colour match. So, for example, white and orange script and graphic elements upon the various backgrounds (infographics style and wallpaper) are hard to read and to perceive. The main page is overloaded with material types: the big introductory section using the drop down navigation is followed by a text block, slideshow tabs, then tab navigation elements follow, a block with a play-the-video button which turns out to be just a link to an advertised newly created or added course. The text block below represents the content of the previous text block about the platform advantages, then slideshow with partner establishments follows and, finally, there is a con- tact and impressum block. The profile button is the only highlighted orange button in the drop-down menu, which is a direct call-to-action piece of content but its title in Ukrainian 'Cabinet' is confusing. An inscription like Login, User's profile or Account would better fit the button directing a participant to their courses. The resume of the main page review reveals strict and concise design, but it is overloaded with information due to its duplication.

In contrast to the main page, the introduction pages of specific courses have linear information representation corresponding to the strict content grid which is really helpful for comparing courses from different educators and choosing the suitable one. Every course description represents the following issues: a short course description (course goals, content compilers and educational organisation, syllabus, course duration, tutor profiles, certificate awarding terms, frequently asked questions section). Within courses, a separate block with answers and completed tasks of other students with the possibility of commenting and sharing their own answers gained the students' approval. Nevertheless, the design deficiencies are a progress line where only icons and not task types are displayed and using a mix of two languages in the progress section: the main menu in the course and the inscriptions of the embedded progress graph are in Russian, and all the text constituents are displayed in Ukrainian.

The mobile version of the site is the example of the adaptive web design and the content grid is transformed accordingly to users' swipes into a narrower but longer table. Nevertheless, the length of the main page and its content suggest that fixed long-scrolling would be more userfriendly than long-scrolling mobile version design. The fixed sign-in-block and course cycle drop-down positions would be sufficient for the front page users, especially for experienced Prometheus platform students.

The English for Career Development course on Prometheus was created by the University of Pennsylvania and the link to the original Coursera website is provided in the course description. The explanations in Ukrainian on how to use the Prometheus course are circumstantial and clear, the edited screenshots are of great assistance for anyone who would like to get an illustrative step-bystep instruction. There is also a strong recommendation to use the discussion section of the platform. The forum offers a great number of possibilities to speak out, to seek other participants' support and answers to puzzling tasks as well as communicative means to receive adequate feedback. The course attendants are welcome to download the certificate of completion, but the name validation is not implemented in the user account register form, just the options of the logging in via social networks. A verified certificate is issued upon fee payment and submitting web camera photos of user's watching the course lectures and their passports scans.

The content of the course includes texts, videos and quizzes. The texts are represented in two variants - for the Basic version of the reading (CEF Level A2-B1) and the challenging task (CEF Level B1) and a course participant can opt for any or both versions. Video tasks are the most appealing source of information according to the stu- 
dents' review because of the video player which playing rate can be customized (from 0.50 to 2.0) and side subtitles accompany the narrative voice. Quiz questions are displayed on the same page, so that the viewers could replay the video in case of their uncertainty. The video content quiz is not assessed whereas reading task quizzes are located on a different webpage because only four attempts to solve the test are allowed. The course has been adapted by Ukrainian compilers effectively, the course description is instructive, but the progress line is confusing and defective in the platform mobile version. On the whole, the English for Career Development course is of great assistance to attendants who need to advance in separate themes and who do not strive for the course completion and are not aimed at obtaining the certificate.

The analysis of the platforms in terms of their main and distinguishing features is presented in table 3 .

The teachers of computer science at Bogdan Khmelnitsky Melitopol State Pedagogical University have selected 10 online courses in disciplines which are crucial for future IT specialists. In order to ensure the impartial analysis of the mentioned above MOOC platforms concerning user-friendliness, design and layout effectiveness, as well as content relevance for prospective IT experts, three courses in cybersecurity have been recommended to the undergraduates of both universities. The enrolled students have submitted their grading as course users and potential course developers or facilitators. According to their assessment the most progressive approach demonstrates the Coursera platform: it offers a complex of four courses (the total duration is five months), each course is aimed at training the specific skills. The analysed course is Introduction to Cybersecurity for Business. It contains numerous videos and self-study text blocks on the most frequently occurring security issues. The MOOC FutureLearn platform has been ranked second. The course explains security challenges, cyber security laws, and risk analysis and management strategies. The distinguishing feature of this course is training cyber security and cryptography terminology - the ability to describe and explain their own routine tasks, duties and work results as a cyber security expert to non-specialists is rated highly by Ukrainian IT undergraduates. The Prometheus platform has been ranked third, but the course users have appreciated the learning material provided by the Ukrainian Zillya! antivirus laboratory. They recommend this course to public at large and they stress its intelligibility for non-experts.

The summarized opinion reveals that all the cyber security courses contain foremost concepts and strategies in specific topics, but the course completion depends on a user's need to be awarded a certificate of achievement.

The third aspect of investigating learning via online courses was the voluntary enrolling in the soft skills courses, selected by the study group teachers. The participants have chosen the course according to their preference for one of the analysed by them MOOC platforms and for the most appealing type and way of thinking (creative thinking, logical and critical thinking, design thinking) which they would like to master or enhance. The students' evaluation does not contain comparison with other two courses because of personal inclination and personality type.

\section{Conclusions}

Online platforms are highly demanded by undergraduates and teaching staff due to temporary challenges, need to correspond to job market globalization tendencies and individual lifelong learning concept appreciation. The courses presented on solid MOOC platforms are compiled by reputable educators, contain cutting-edge concepts aimed at forming and developing professionally and socially relevant skills. The online courses for specific purposes are of great assistance as a part of university syllabi. Specific topics within an online course are highly demanded for filling gaps in one's knowledge. Some courses have a linear content structure, but most online assets encourage studying the most demanded topics first, nevertheless, an individual pace is strictly limited which is a powerful incentive to complete tasks in time. In respect to psychological preferences most IT undergraduates are attracted to online learning platforms due to prior evaluation objectiveness and absence of competition with groupmates. Adaptive web design allows easy transition between desktop and mobile versions, the platforms demonstrate user-friendliness and intelligibility for entry-level participants. The intercultural aspect of the Coursera and FutureLearn platforms in the form of a forum or a community is another distinguishing feature highly appreciated by Ukrainian users. The Ukrainian Prometheus platform provides mostly adapted courses of the prominent foreign universities, which is beneficial for users who strive to improve their knowledge and skills. To sum up, MOOC platforms tend to become more demanded and in complex with university education promise to ensure delivering highly qualified graduates and job seekers for both Ukrainian and foreign employers.

\section{References}

[1] O. Burov, A. Kiv, S. Semerikov, A. Striuk, M. Striuk, L. Kolgatina, I. Oliinyk, CEUR Workshop Proceedings 2731, 1 (2020)

[2] A. Kiv, P. Hryhoruk, I. Khvostina, V. Solovieva, V. Soloviev, S. Semerikov, CEUR Workshop Proceedings 2713, 1 (2020)

[3] S. Semerikov, S. Chukharev, S. Sakhno, A. Striuk, V. Osadchyi, V. Solovieva, T. Vakaliuk, P. Nechypurenko, O. Bondarenko, H. Danylchuk, E3S Web of Conferences 166 (2020)

[4] V.N. Soloviev, A.O. Bielinskyi, N.A. Kharadzjan, CEUR Workshop Proceedings 2832, 24 (2020)

[5] A. Bielinskyi, I. Khvostina, A. Mamanazarov, A. Matviychuk, S. Semerikov, O. Serdyuk, V. Solovieva, V. Soloviev, IOP Conference Series: Earth and Environmental Science 628 (2021)

[6] N.S. Ponomareva, Journal of Physics: Conference Series 1840, 012035 (2021) 
Table 3. Main and distinguishing features of the MOOC platforms (Prometheus, FutureLearn, Coursera)

\begin{tabular}{|c|c|c|c|}
\hline Courses & Prometheus & FutureLearn & Coursera \\
\hline \multirow[t]{2}{*}{ Design } & Adaptive design & Adaptive design & Adaptive design \\
\hline & $\begin{array}{l}\text { Information overload } \\
\text { on the main page }\end{array}$ & $\begin{array}{l}\text { Bright palette including } \\
\text { neon colours }\end{array}$ & Appealing colour scheme \\
\hline \multirow[t]{4}{*}{ Layout } & Strict grid & Negative space layout & Strict grid \\
\hline & User-friendly navigation, & Tablet aspect ratio & Visual ergonomics \\
\hline & intelligible menus and tabs & Simplified information display & Side menu compatible \\
\hline & $\begin{array}{l}\text { Progress bars (defective } \\
\text { display in the mobile version) }\end{array}$ & $\begin{array}{l}\text { Beneficial for long-term learning } \\
\text { using mobile or portable devices }\end{array}$ & with wide-screen devices \\
\hline \multirow[t]{4}{*}{ Content } & Texts & Texts & Texts \\
\hline & Video spots & Video spots & Video spots \\
\hline & Video materials & Video materials & Video materials \\
\hline & & $\begin{array}{l}\text { Facebook live broadcast } \\
\text { Paid content upgrade }\end{array}$ & Paid content upgrade \\
\hline Communities & $\begin{array}{l}\text { Separate block with written } \\
\text { assignments with the } \\
\text { possibility of commenting }\end{array}$ & $\begin{array}{l}\text { Separate block with written } \\
\text { assignments with the } \\
\text { possibility of commenting }\end{array}$ & $\begin{array}{l}\text { Separate block with written } \\
\text { assignments with the } \\
\text { possibility of commenting }\end{array}$ \\
\hline Documentation & Free certificate & $\begin{array}{l}\text { Two types of certificates: } \\
\text { free certificate, } \\
\text { paid certificate }\end{array}$ & $\begin{array}{l}\text { Two types of certificates: } \\
\text { free certificate, } \\
\text { verified certificate }\end{array}$ \\
\hline \multirow[t]{2}{*}{ Applications } & Android:Prometheus & Android - & $\begin{array}{l}\text { Android: Coursera: } \\
\text { Online courses }\end{array}$ \\
\hline & AppStore - & AppStore - & $\begin{array}{l}\text { AppStore: Coursera: } \\
\text { Learn new skills }\end{array}$ \\
\hline
\end{tabular}

[7] S. Semerikov, H. Kucherova, V. Los, D. Ocheretin, CEUR Workshop Proceedings 2845, 22 (2021)

[8] M. Velykodna, Psychodynamic Practice 27, 10 (2021)

[9] C. Impey, Massive online open courses see exponential growth during COVID-19 pandemic (2020), https://tinyurl.com/246amnyv

[10] Z. Seidametova, CEUR Workshop Proceedings 2104, 462 (2018)

[11] L. Panchenko, I. Muzyka, CEUR Workshop Proceedings 2547, 168 (2020)

[12] I.S. Zinovieva, V.O. Artemchuk, A.V. Iatsyshyn, Y.O. Romanenko, O.O. Popov, V.O. Kovach, D.V. Taraduda, A.V. Iatsyshyn, Journal of Physics: Conference Series (2021, in press)

[13] J. Warner, MOOCs Are "Dead." What's Next? Uh-oh (2017), https://www. insidehighered.com/blogs/just-visiting/ moocs-are-dead-whats-next-uh-oh

[14] A. McAuley, B. Stewart, G. Siemens, D. Cormier, The MOOC model for digital practice (CC Attribution, 2010)

[15] Massive open online course (2020), https://en. wikipedia.org/w/index . php?title=Massive_ open_online_course\&oldid=984394058

[16] M. Perifanou, LangMOOCs - Intellectual Output 2 Language Massive Open Online Courses (Erasmus, 2015)

[17] Questions for Learners (Society) (2020), https://mooc-book.eu/index/learners/ key-questions/
[18] N. Alhazzani, Social Sciences \& Humanities Open 2, 100030 (2020)

[19] S. Gallagher, J. Palmer, The Pandemic Pushed Universities Online. The Change Was Long Overdue (2020), https://tinyurl. com/muuhhsuz

[20] J. Reich, J. Ruipérez-Valiente, Science 363, 130 (2019)

[21] D. Peters, MOOCs are not dead, but evolving (2018), https://www . universityaffairs.ca/news/ news-article/moocs-not-dead-evolving/

[22] S. Lohr, Remember the MOOCs? After Near-Death, They're Booming (2020), https: //www . nytimes. com/2020/05/26/ technology/moocs-online-learning.html

[23] D. Shah, By the Numbers: MOOCs During the Pandemic (2020), https: //www . classcentral . com/ report/mooc-stats-pandemic/

[24] T. Chen, L. Peng, B. Jing, C. Wu, J. Yang, G. Cong, Sustainability 12 (2020)

[25] L. Ma, Z. Zhang, N. Zhang, Journal of Physics: Conference Series 1544, 012123 (2020)

[26] S. Symonenko, N. Zaitseva, V. Osadchyi, K. Osadcha, E. Shmeltser, CEUR Workshop Proceedings 2547, 37 (2020)

[27] V. Lemeshchenko-Lagoda, I. Kryvonos, O. Kolodii, E3S Web of Conferences 166 (2020)

[28] I. Duru, A.S. Sunar, S. White, B. Diri, G. Dogan, Sustainability 11 (2019)

[29] K.R.M. Rafiq, H. Hashim, M.M. Yunus, Journal of Physics: Conference Series 1424, 012033 (2019) 
[30] A. Qaffas, K. Kaabi, R. Shadiev, F. Essalmi, Smart Learning Environments 7, 14 (2020)

[31] R. Furtado, How to learn online in the middle of a pandemic (2020), https://tinyurl.com/ 3sxtz6d6

[32] P. Raine, CALL-EJ 19, 125 (2018)

[33] M.J. Israel, The International Review of Research in Open and Distributed Learning 16, 102 (2015)

[34] D. Bruff, D. Fisher, K. McEwen, B. Smith, Journal of Online Learning and Teaching 9, 187 (2013)
[35] N. Rubaai, H. Hashim, Inter International Journal of Innovative Technology and Exploring Engineering 8 , 114 (2019)

[36] M. Perifanou, A. Economides, MOOCs for foreign language learning: an effort to explore and evaluate the first practices, in INTED2014 Proceedings (IATED, 2014), 8th International Technology, Education and Development Conference, pp. 35613570, ISBN 978-84-616-8412-0, ISSN 2340-1079 